\title{
Component Authentication and Standardisation of an Anti-atherosclerotic Herbal Formulation-GSTC3
}

\author{
Jeksy Jos Manalil, Indu Muraleedharan Suseela, Smitha Koyickalmadhom Ramavarma, Arunaksharan Narayanankutty and Achuthan \\ Chathrattil Raghavamenon*
}

Department of Biochemistry, Amala Cancer Research Centre, Recognized by University of Calicut, Amala Nagar, Thrissur-680 555, India.

\begin{abstract}
Context: Polyherbal drugs in traditional medicine have been time-tested for treatment of a wide variety of chronic ailments. Aims: To determine constituent components in an in-house designed polyherbal formulation GSTC3 and evaluation of consistency in preparation. Settings and Design: In this study, a hypolipidemic formulation was created using well known plant extracts such as Commiphora mukul (Hook. ex Stocks.) Eng. (Burseraceae), Salacia reticulata Wight (Celastraceae), Terminalia arjuna (Roxb.) Wight and Arn (Combretaceae) and Curcuma longa Linn (Zingiberaceae). Methods and Material: The authentication of individual plant powders was performed using techniques such as powder microscopy and characterised according to Ayurvedic pharmacopeia of India. Phytochemical screening, HPTLC analysis and physicochemical parameters were also determined. Results: The powder microscopic analysis of the individual components served as an authentication for source of plants used. Phytochemical screening ascertained that active classes of compounds reported in the individual extracts such as steroids, terpenoids and polyphenols came into the formulation. Finally, HPTLC analysis of three different batches of GSTC3 ensured stability and integrity in batch to batch preparations. Conclusion: Experimental studies have revealed the antioxidant, antiinflammatory, anti-lipidemic and anti-thrombotic efficacy of GSTC3. This standardisation procedure is essential for further development of GSTC3 into an efficient anti-atherosclerotic drug candidate.
\end{abstract}

Key words: HPTLC, Pharmacognosy, Polyherbal formulation, Powder microscopy, Phytochemical screening.

\section{SUMMARY}

- GSTC is an anti-atherosclerotic polyherbal formulation developed from four individual medicinal plants.

- Powder microscopic analysis of the individual components of GSTC3 served as an authentication of source plant.

- Phytochemical screening ascertained the presence of steroids, terpenoids and polyphenols in the formulation.
- HPTLC analysis of three different batches of GSTC3 ensured stability and integrity among batch to batch preparations.

- Physicochemical analysis showed the feasibility of GSTC3 in its further development as an efficient anti-atherosclerotic drug candidate.

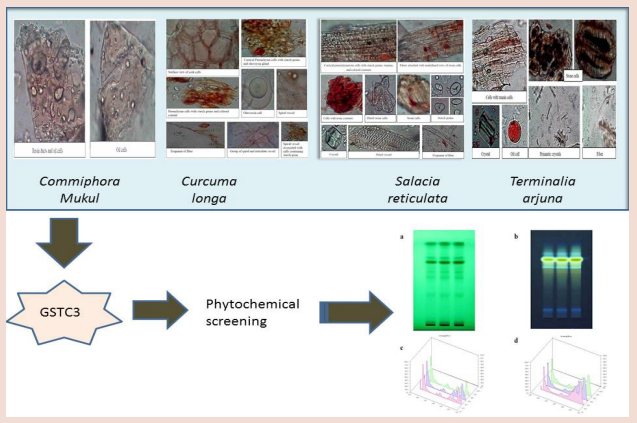

\section{PICTORIAL ABSTRACT}

Abbreviations used: GSTC3: Polyherbal formulation, HPTLC: High Performance Thin Layer Chromatography, EU: European Union, API: Ayurvedic Pharmacopeia of India, BSI: Botanical Survey of India.

\section{Correspondence:}

Dr. Achuthan Chathrattil Raghavamenon, Associate Professor, Department of Biochemistry, Amala Cancer Research Centre, Amala Nagar, Thrissur-680 555, India.

Phone no: 0091-9567988570, Fax no: 0091-2307968

Email: achuthanm@gmail.com

DOI : 10.5530/pj.2015.6.4

\section{INTRODUCTION}

The knowledge passed down through centuries has been time-tested and hence forth priceless. The most prominent examples being traditional systems of medicine such as Ayurveda, Unani and that of the Chinese. Even with the advent of scientific approach for treatment of diseases, traditional systems of medicine especially those related to natural sources such as medicinal plants play a deep-rooted role in modern lifestyles. With the ever-increasing use of such herbal medicines and resulting expansion of the herbal medicines market, safety has become a major concern for both health authorities and the general public itself. ${ }^{1}$ To ratify this predicament, modern scientific approaches may be employed to ensure safety standards while ensuring maximum biological efficacy in the production and marketing of such proprietary medicines. For example, detailed quality requirements for herbal medicinal products on the European market are mentioned in the pharmaceutical legislation of the European Union (EU). ${ }^{2}$

As medicinal herbs and herbal formulations are generally considered to be safer than the conventional drugs, traditional systems of medicine or plant-based drugs are attractive and economical alternative treatments because of their professed efficacy in curing diseases. ${ }^{3}$ Herbal prescriptions are however most frequently given to patients as complex formulations containing multiple herbs. Unwittingly, this approach amounts to the administration of several chemical entities at once; the underlying theory being that interactions among the chemicals present in different herbs in a formula exert synergistic pharmacodynamic actions and neutralize the adverse effects and toxicities of specific individual chemicals. ${ }^{4}$ In such an attempt to develop an anti-atherosclerotic drug candidate, three different polyherbal formulations were prepared consisting of different proportions of extracts of Commiphora mukul (Hook. ex Stocks.) Eng. (Burseraceae) resin, Salacia reticulata Wight (Celastraceae) root, Terminalia arjuna (Roxb.) Wight and Arn (Combretaceae) bark and Curcuma longa Linn (Zingiberaceae) rhizome. The selection of individual plants and preparation of the extracts were based on their scientifically proven efficacy in reducing the risks associated with atherosclerosis. ${ }^{5-8}$ The active components and their modes of actions have also been re- 
ported. ${ }^{9-12}$ The individual plant powders of the formulation and the formulation itself in different proportions were tested using various in vitro and in vivo models and are found to have antioxidant, antithrombotic, anti-inflammatory and anti-lipidemic efficacy. The standardisation of the most active formulation GSTC3 was then the next step to be done together with testing for uniqueness in batch to batch preparation.

In India, the ayurvedic pharmacopeia (API) records various parameters to be checked in the preparation and use of such products. ${ }^{13}$ Here such a study is being undertaken to characterize the polyherbal formulation GSTC3.

\section{SUBJECTS AND METHODS}

\section{Source of plant materials}

Gum resin of Commiphora mukul, root of Salacia reticulata, bark of Terminalia arjuna and rhizome of Curcuma longa were obtained from the Preparation Unit of Amala Ayurvedic Hospital and Research Centre, Thrissur, Kerala. They were authenticated by the Botanical Survey of India (BSI) using herbarium sheets and voucher specimens were maintained with the BSI Sp. Nos: 77360, 61127, 43886 and 63180, respectively at the herbarium of Amala Ayurvedic Research Centre.

\section{Preparation of plant materials for pharmacognosy}

Fresh plant materials were washed under running tap water, air dried, pulverized to fine powder and stored in airtight bottles with proper labelling for future use.

\section{Powder microscopy}

The powder characteristics of all four plant constituents were carried out. The slides were prepared using a small portion of each sample mounted in $50 \%$ glycerine and were observed under a microscope.

\section{Physicochemical evaluations}

\section{Determination of loss on drying}

About $10 \mathrm{~g}$ of drug (without preliminary drying) after accurate weighing was taken in a tarred evaporating dish. This was subjected to drying at $105^{\circ} \mathrm{C}$ for $5 \mathrm{~h}$ and weighed again. The drying and weighing process was continued for 1 hour intervals until difference between two successive weighing corresponds to not more than $0.25 \%$.

\section{Determination of total ash}

About 2 to $3 \mathrm{~g}$ accurately weighed, ground drug was incinerated in a tarred platinum or silica dish at room temperature not exceeding $450^{\circ} \mathrm{C}$ until free from carbon and then cooled and weighed. The percentage of ash with reference to the air-dried drug was calculated.

\section{Determination of acid insoluble ash}

The ash obtained in the earlier process was boiled for 5 minutes with $25 \mathrm{~mL}$ of dilute hydrochloric acid. The insoluble matter was collected in a gooch crucible, boiled, dried and weighed. The percentage of acidinsoluble ash with reference to the air dried drug was calculated.

Determination of water soluble and alcohol soluble extractives

Around $5 \mathrm{~g}$ of the air dried drug was macerated, coarsely powdered and kept in $100 \mathrm{~mL}$ of water or alcohol for determination of water or alcohol soluble extractives respectively, in a closed flask for twenty-four hours, shaking frequently during six hours and allowed to stand for eighteen hours. After filtering rapidly, taking precautions against loss of solvent, $25 \mathrm{~mL}$ of the filtrate was evaporated to dryness in a tarred flat bottomed shallow dish, and dried at $105^{\circ} \mathrm{C}$, to constant weight and weighed.

\section{Phytochemical screening ${ }^{14,15}$}

\section{Test for steroids and triterpenoids}

Liebermann Burchard test: The formulation was mixed with few drops of acetic anhydride, boiled and cooled. Concentrated sulphuric acid was then added from the sides of the test tube and observed for formation of a brown ring at the junction of two layers. Green colouration of the upper layer indicate steroids and the formation of deep red colour in the lower layer indicate a positive test for triterpenoids.

Test for cardiac glycosides

Keller Killiani Test: Test solution was treated with few drops of glacial acetic acid and a drop of ferric chloride solution was added and mixed. Concentrated sulphuric acid was added slowly and observed for the formation of two layers. A brown ring at the interface indicated the presence of deoxysugar molecules characteristic of cardenolides.

Test for saponins

Foam test: Test solution was mixed with water and shaken and observed for the formation of froth, which is stable for 15 minutes giving a positive result.

\section{Test for flavonoids}

Ferric chloride test: Test solution when treated with few drops of ferric chloride solution would result in the formation of blackish red colour indicating flavonoids.

Alkaline reagent test: Test solution when treated with sodium hydroxide solution, shows increase in the intensity of yellow colour which would become colourless on addition of few drops of dilute hydrochloric acid, indicating the presence of flavonoids.

\section{Test for carbohydrates}

Benedict's test: Test solution was mixed with few drops of Benedict's reagent (alkaline solution containing cupric citrate complex) and boiled in water bath, observed for the formation of reddish brown precipitate to show a positive result for the presence of carbohydrate.

\section{Test for alkaloids}

Hager's test: Test solution was treated with few drops of saturated picric acid solution. Formation of yellow precipitate indicates presence of alkaloids.

\section{HPTLC Fingerprinting}

Each plant extract was prepared as described by previous literature that gave a scientific basis for medicinal activity. Accordingly, C. mukul resin was extracted using petroleum ether ${ }^{16}$ S. reticulata root using water, ${ }^{17}$ bark of T. arjuna ${ }^{18}$ and rhizome of C. longa using methanol. ${ }^{19}$ Approximately, $20 \mathrm{~g}$ of each powder was extracted with $150 \mathrm{~mL}$ of respective solvent using a magnetic stirrer for $72 \mathrm{~h}$; changing solvent every $24 \mathrm{~h}$. Each time the supernatants obtained by centrifugation were collected. Finally the supernatants were pooled, concentrated and evaporated to dryness in a water bath. Individual solvent free extracts were stored separately in air-tight bottles and kept below $4^{\circ} \mathrm{C}$. For preparation of GSTC3, preselected weights of the solvent free extract were taken; S. reticulata was dissolved in water while the others were dissolved in propylene glycol for phytochemical analysis and methanol for HPTLC analysis.

Samples from three different batches of GSTC3 preparations were applied on to Aluminum backed pre-coated Merck silica gel plate $60 \mathrm{~F}_{254}$ plate $(10 \times 10 \mathrm{~cm})$ using Camag automatic TLC sampler 4 attached to Camag HPTLC system. Approximately $3 \mu \mathrm{L}$ each of all test solutions were loaded in the form of bands with bandwidth of $8 \mathrm{~mm}$ using Hamilton syringe $(100 \mu \mathrm{L})$. The plate was developed in a solvent system, Toluene: 


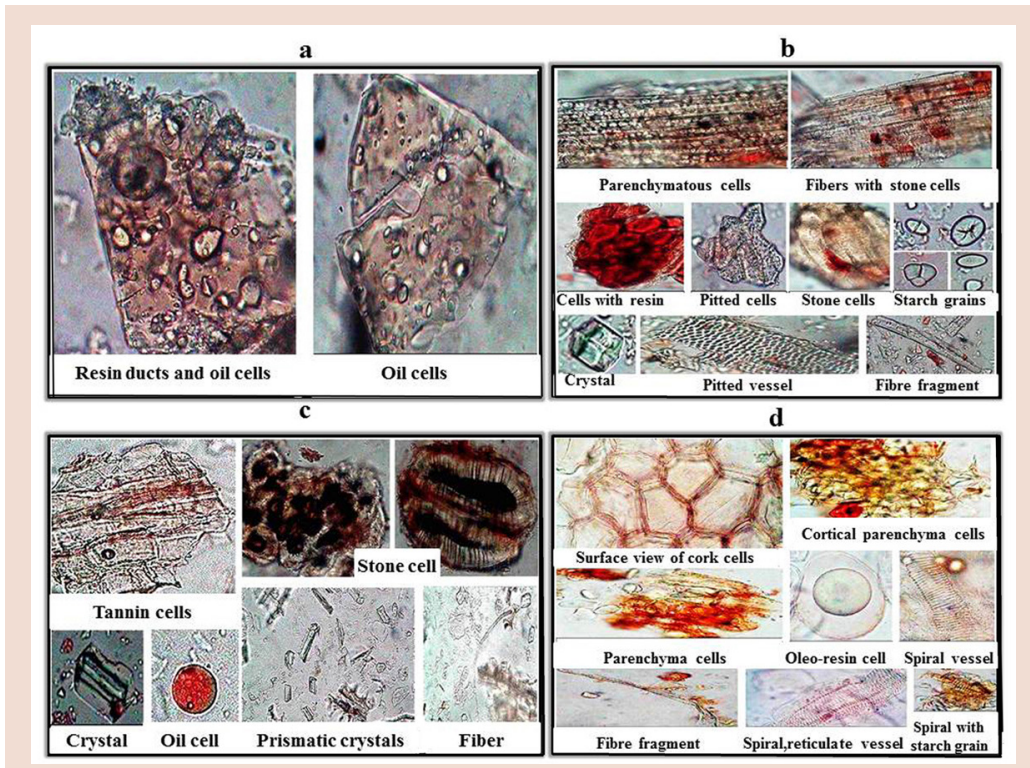

Figure 1: Powder microscopic analysis of (a) Commiphora mukul, (b) Salacia reticulata, (c) Terminalia arjuna and (d) Curcuma longa

Table 1: Physico-chemical parameters of individual constituents of GSTC3

\begin{tabular}{ccccc}
\hline Parameters (\%w/w) & Commiphora mukul & Salacia reticulata & Terminalia arjuna & Curcuma longa \\
\hline $\begin{array}{c}\text { Moisture content } \\
\text { Water soluble }\end{array}$ & 5.96 & 6.45 & 8.48 & 9.64 \\
extractive value & 22.85 & 6.95 & 13.31 & 12.12 \\
$\begin{array}{c}\text { Alcohol soluble } \\
\text { extractive value }\end{array}$ & 31.01 & 8.90 & 12.48 & 5.79 \\
$\quad \begin{array}{l}\text { Total ash } \\
\text { Acid insoluble ash }\end{array}$ & 17.37 & 4.43 & 7.88 & 7.98 \\
Volatile oil & 11.06 & 1.39 & 2.08 & 1.15 \\
\hline
\end{tabular}

Ethyl acetate: formic acid (7:3:0.2) using a twin trough chamber upto a distance of $9 \mathrm{~cm}$. After the run, the plate was observed under UV light at $254 \mathrm{~nm}$ and $366 \mathrm{~nm}$. The $\mathrm{R}_{\mathrm{f}}$ value and color of the resolved bands were recorded. Densitometric scanning of the plates at $254 \mathrm{~nm}$ and $366 \mathrm{~nm}$ was done by using Camag TLC scanner 3 .

\section{RESULTS}

\section{Powder microscopy}

Microscopic analysis of Commiphora mukul, showed the presence of resin ducts and oil cells (Figure 1a). Salacia reticulata on analysis showed presence of cortical parenchymatous cells with starch grains, stone cells and pitted stone cells (Figure 1b). Terminalia arjuna powder showed the presence of tannin cells, stone cells and fibers (Figure 1c). Curcuma longa also showed characteristic cork cells, oleo-resin cells, spiral and reticulate vessels (Figure $1 \mathrm{~d}$ ).

\section{Physico-chemical parameters}

Physico-chemical parameters for purity assessment and standardization of individual plant component were checked according to procedures cited in API. Table 1 shows the physiochemical parameters obtained for the dried powders of individual plant components.
Table 2: Phytochemical Analysis of GSTC3

\begin{tabular}{cc}
\hline Components & GSTC3 \\
\hline Alkaloids & ++ \\
Glycosides & + \\
Flavonoids & + \\
Tannins & + \\
Steroids & ++ \\
Triterpenoids & ++ \\
Phenolics & + \\
Carbohydrates & +++ \\
Saponins & +++ \\
\hline
\end{tabular}

Presence: + + + :Intense; + +: Moderate; +: Slight.

\section{Phytochemical analysis}

A variety of biologically active phytochemicals were found to be present in the formulation including phenols, flavonoids, steroids etc. (Table 2). 


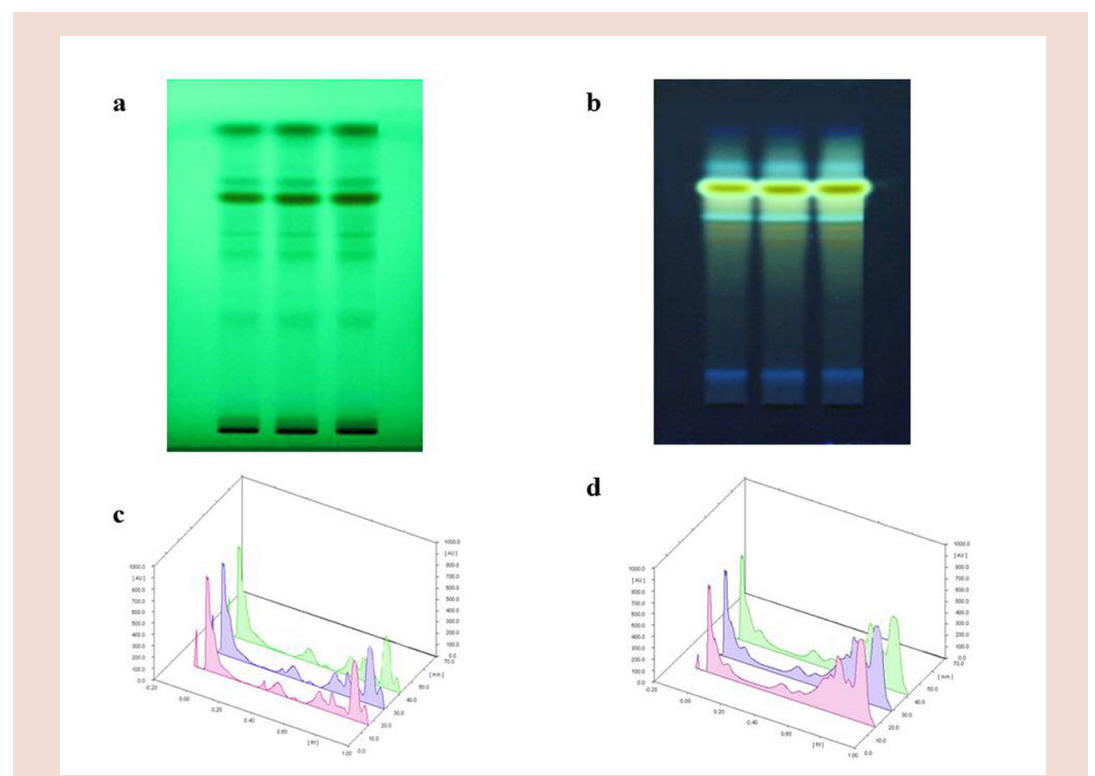

Figure 2: Visualization of bands formed under (a) $254 \mathrm{~nm}$, (b) $366 \mathrm{~nm}$. HPTLC fingerprinting chromatogram at (c) $254 \mathrm{~nm}$ and (d) $366 \mathrm{~nm}$

\section{HPTLC profiling}

HPTLC finger printing profile of GSTC3 were developed in Toluene: Ethyl acetate: Formic acid (5: 1.5: $0.5 \mathrm{v} / \mathrm{v}$ ) solvent system. Under 254 $\mathrm{nm}$, it showed 5 spots with $\mathrm{R}_{\mathrm{f}}$ values $0.37,0.57,0.64,0.77,0.81$ (all dark bands); under $366 \mathrm{~nm}$ it showed 6 spots with $\mathrm{R}_{\mathrm{f}}$ values of 0.11 (blue), 0.57 (brown), 0.62 (brown), 0.66 (cream), 0.76 (yellow), 0.83 (cream). In both the visualizations at 254 and $366 \mathrm{~nm}$ (Figure $2 \mathrm{a}$ and b) as well as the overlapping graphical representations (Figure $2 \mathrm{c}$ and d), all three batches tested exhibited similar banding pattern.

\section{DISCUSSION}

The use of herbs has been the mainstay of treatment for a variety of human illnesses and is an essential part of culturally-based healing traditions in many societies and countries. Also, herbs, including Chinese herbs, are being incorporated as remedies for disease management and treatment in Western countries, being regarded as dietary supplements. ${ }^{20}$ Standardization of herbal formulations is essential in order to assess quality of drugs, based on the concentration of their active principles, physical, chemical and phytochemical parameters. The quality of herbal formulations is of paramount importance in order to justify their acceptability in modern system of medicine. The physicochemical parameters, quantitative analysis and HPTLC fingerprint profiles together may be used for quality evaluation and the standardization of compound formulations at the primary stage.

The poly herbal formulation GSTC3 is a reddish yellow suspension made up of extracts from gum resin of Commiphora mukul, root bark of Salacia reticulata, bark of Terminalia arjuna and rhizome of Curcuma longa. Oleo gum resin extracted from the Commiphora mukul tree is a very complex mixture of gum, minerals, essential oils, terpenes, sterols, ferrulates, flavanones and sterones. Its active constituents, the $\mathrm{Z}$ - and $\mathrm{E}$ guggulsterones, have been demonstrated to exhibit their biological activities by binding to nuclear receptors and modulating the expression of proteins involved in carcinogenic activities. ${ }^{21}$ The powder microscopic analysis reveals the presence of resin ducts and oil cells which when compared to the API classification is typical of C. mukul. This authenticates the plant sample used. Physiochemical standards were minimum to the standard values described in the API. This indicates the grade of the used C. mukul resin sample. Similar characteristic crystal structures were observed with $S$. reticulata, $T$. arjuna and $C$. longa suggesting their authenticity. Purity of the powder samples are evident from the minimum values obtained through their physico-chemical characteristic analysis. Polyphenols, di and triterpenes, Epigallocatechin, mangiferin, (-)-4'-Omethylepigallocatechin, tannins and salacinol have been isolated from the roots of $S$. reticulata. ${ }^{22}$

Phytochemical screening of Terminalia arjuna has shown the active compounds present in high concentration to be phytosterols, lactones, flavonoids, phenolic compounds, tannins and glycosides..$^{18}$ Major polyphenolic phytochemicals including curcumin have been isolated from the rhizome of the plant Curcuma longa (turmeric) that has been traditionally used for the treatment of inflammation for centuries. ${ }^{23}$

Most of these reported phytochemicals in individual plant components have showed their presence in GSTC3. Even though not quantitatively determined, the presence of active principles in the combined formulation suggests the possibility that an additive/synergetic action of these active principles would be exhibited by GSTC3. Batch to batch preparation of this polyherbal formulation is found to be consistent as revealed by the HTPLC results. In our earlier studies GSTC3 have been found to be a good antioxidant and ant-inflammatory agent, both in vitro and in vivo. ${ }^{24}$ The anti-atherosclerotic potential of the formulation has also been demonstrated through its efficacy in preventing serum oxidation, platelet peroxidation and hypolipidemic activity in high fat-diet fed rats with lethal dose $50\left(\mathrm{LD}_{50}\right)$ being above $5 \mathrm{~g} / \mathrm{kg}$ bwt. ${ }^{25}$

Based on these anti-atherosclerotic activities and its nontoxic nature, as well as the fact that both the individual components and the prepared formulation maintain the API standards, GSTC3 could prove to be a fruitful drug candidate against atherosclerosis. The consistency in batch to batch preparation of GSTC3 suggests its unique preparation.

\section{ACKNOWLEDGEMENT}

The authors are grateful to INSPIRE program, Department of Science and Technology, Government of India for financial support as research scholarship. We also express our gratitude to Ms. Deepthi and Ms. Nimisha of Vaidyaratnam Oushadhashala, Ollur. 


\section{CONFLICT OF INTEREST}

The authors declare no conflict of interest.

\section{REFERENCES}

1. Gurib-Fakim A. Medicinal plants: traditions of yesterday and drugs of tomorrow. Mol Aspects Med. 2006; 27(1): 1-93.

2. Kroes $\mathrm{BH}$. The legal framework governing the quality of (traditional) herbal medicinal products in the European Union. J Ethnopharmacol. 2014; $158 \mathrm{Pt}$ $B(1)$ : 449-53.

3. Subramaneyaan M, Yasmeen S, Arora VK, Tripathi AK, Banerjee BD, Ahmed RS Safety evaluation and therapeutic efficacy of Habb-e-Asgand, a commonly used antirheumatic polyherbal Unani formulation. Altern Ther Health Med. 2013 19(5): 52-9.

4. Hsieh TC, Wu JM. Differential control of growth, cell cycle progression, and gene expression in human estrogen receptor positive MCF-7 breast cancer cells by extracts derived from polysaccharopeptide I'm-Yunity and Danshen and their combination. Int J Oncol. 2006; 29(5): 1215-22.

5. Gupta SC, Sung B, Kim JH, Prasad S, Li S, Aggarwal BB. Multitargeting by turmeric, the golden spice: From kitchen to clinic. Mol Nutr Food Res. 2013; 57(9): 1510-28.

6. Yoshikawa M, Shimoda H, Nishida N, Takada M, Matsuda H. Salacia reticulata and its polyphenolic constituents with lipase inhibitory and lipolytic activities have mild antiobesity effects in rats. J Nutr. 2002; 132(7): 1819-24.

7. Subramaniam S, Subramaniam R, Rajapandian S, Uthrapathi S, Gnanamanickam VR, Dubey GP. Anti-Atherogenic Activity of Ethanolic Fraction of Terminalia arjuna Bark on Hypercholesterolemic Rabbits. Evid-Based Compl Alt: eCAM. 2011; 2011(1): 487-916.

8. Deng R. Therapeutic effects of guggul and its constituent guggulsterone: cardiovascular benefits. Cardiovasc Drug Rev. 2007; 25(4): 375-90.

9. Shah R, Gulati V, Palombo EA. Pharmacological properties of guggulsterones, the major active components of gum guggul. Phytother Res. 2012; 26(11): 1594-605.

10. Saxena M, Faridi U, Mishra R, Gupta MM, Darokar MP, Srivastava SK, et al. Cytotoxic agents from Terminalia arjuna. Planta Med. 2007; 73(14): 1486-90.

11. Chen $Y$, Liu WH, Chen BL, Fan L, Han Y, Wang G, et al. Plant polyphenol curcumin significantly affects CYP1A2 and CYP2A6 activity in healthy, male Chinese volunteers. Ann Pharmacother. 2010; 44(6): 1038-45.
12. Yoshikawa M, Shimoda H, Nishida N, Takada M, Matsuda H. Salacia reticulata and its polyphenolic constituents with lipase inhibitory and lipolytic activities have mild antiobesity effects in rats. J Nutr. 2002; 132(7): 1819-24.

13. The Ayurvedic Pharmacopoeia of India. Part - II (Formulations).Vol. I. $1^{\text {st }}$ Edition; Government of India. Ministry of Health and Family Welfare, Department of Ayurveda, Yoga and Naturopathy, Unani, Siddha and Homoeopathy, New Delhi; 2007.

14. Raman N. Phytochemical Technique. New Indian Publishing Agencies: New Delhi; 2006. p. 19.

15. Harborne JB. Phytochemical Methods. New Delhi: Springer (India) Pvt.Ltd; 2005. p. 17.

16. Singh AK, Tripathi SN, Prasad GC. Response of commiphora mukul (guggulu) on melatonin induced hypothyroidism. Anc Sci. Life 1983; 3(2): 85-90.

17. Muraoka O, Morikawa T, Miyake S, Akaki J, Ninomiya K, Yoshikawa M. Quantitative determination of potent alpha-glucosidase inhibitors, salacinol and kotalanol, in Salacia species using liquid chromatography-mass spectrometry. J Pharm Biomed Anal. 2010; 52(5): 770-3.

18. Mandal S, Patra A, Samanta A, Roy S, Mandal A, Mahapatra TD, et al. Analysis of phytochemical profile of Terminalia arjuna bark extract with antioxidative and antimicrobial properties. Asian Pac J Trop Biomed. 2013; 3(12): 960-6.

19. Adaramoye OA, Anjos RM, Almeida MM, Veras RC, Silvia DF, Oliveira FA, et al. Hypotensive and endothelium-independent vasorelaxant effects of methanolic extract from Curcuma longa L. in rats. J Ethnopharmacol. 2009; 124(3): 457-62.

20. Lee KH. Research and future trends in the pharmaceutical development of medicinal herbs from Chinese medicine. Public Health Nutr. 2000; 3(4A): 515-22.

21. Shah R, Gulati V, Palombo EA. Pharmacological properties of guggulsterones, the major active components of gum guggul. Phytother Res. 2012; 26(11): 1594-605.

22. Yoshikawa M, Shimoda H, Nishida N, Takada M, Matsuda H. Salacia reticulata and its polyphenolic constituents with lipase inhibitory and lipolytic activities have mild antiobesity effects in rats. J Nutr. 2002; 132(7): 1819-24.

23. Kanakasabai S, Casalini E, Walline CC, Mo C, Chearwae W, Bright JJ. Differential regulation of $\mathrm{CD} 4(+) \mathrm{T}$ helper cell responses by curcumin in experimental autoimmune encephalomyelitis. J Nutr Biochem. 2012; 23(11): 1498-507.

24. Manalil JJ, Puthanveettil J, Babu TD, Raghavamenon AC. Antioxidant and Anti-inflammatory Properties of a Nontoxic Herbal formulation-GSTC. Int J Pharmtech Res. 2014; 6(1): 924-32.

25. Manalil JJ, Baby M, Ramavarma SK, Suseela IM, Padikkala J, Raghavamenon AC. Development of an anti-atherosclerotic polyherbal formulation-GSTC3. J Environ Pathol Toxicol Oncol. 2015; 34(3): 237-48.

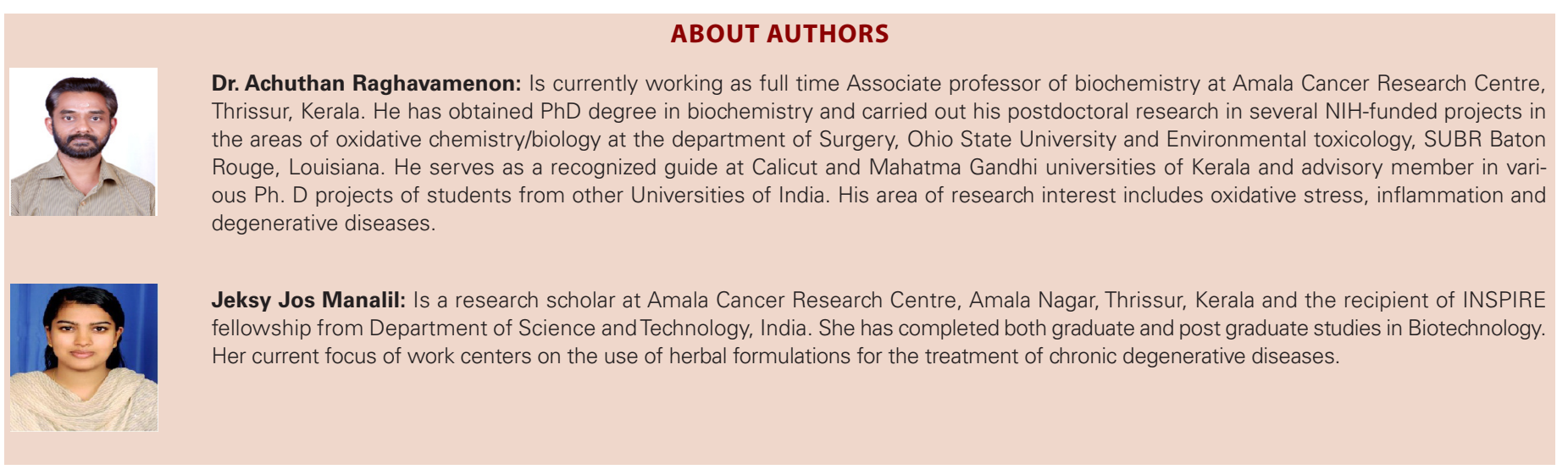

